\title{
Synthesis of liquid crystals materials derived from oxadiazole, isoxazole and tetrazole heterocycles
}

\author{
Daniela Rubia dos Santos, ${ }^{a}$ Ana Gabriela Silva de Oliveira, ${ }^{a}$ Rafael Levi Coelho, ${ }^{a}$ Iêda \\ Maria Begnini, ${ }^{a}$ Rachel Faverzani Magnago, ${ }^{b}$ and Luciano da Silva ${ }^{c}$ \\ ${ }^{a}$ Departamento de Química, Universidade Regional de Blumenau, 89012-900,Blumenau -SC, \\ Brasil \\ ${ }^{b}$ Laboratório de Química das Engenharias - UnidadeTecnológica, Universidade do Sul de Santa \\ Catarina, 88704-900, Tubarão - SC, Brasil \\ ${ }^{c}$ Laboratório de Pesquisa em Energia - Universidade do Vale do Itajaí, 88122-000, São José - \\ SC, Brasil \\ E-mail: luciano.silva@univali.br
}

\begin{abstract}
The synthesis is described of new liquid crystalline heteroaromatic compounds containing the five- membered isoxazole, tetrazole and 1,2,4-oxadiazole rings. Two liquid crystalline series including five- membered heterocycles were synthesized. The compounds with the mesogenic units tetrazole and isoxazole (Series I) showed nematic and smectic C phases, while the compounds with the units tetrazole and 1,2,4-oxadiazole (Series II) presented nematic (N), smectic $\mathrm{C}\left(\mathrm{Sm}_{\mathrm{C}}\right)$, and smectic $\mathrm{A}\left(\mathrm{Sm}_{\mathrm{A}}\right)$ mesophases. The transition temperatures and textures of the mesophases determined were characterized using polarized optical microscopy.
\end{abstract}

Keywords: Liquid crystals, oxadiazole, isoxazole, tetrazole

\section{Introduction}

The design of novel thermotropic liquid crystals as advanced functional materials involves selection of a suitable core fragment, linking group, and terminal functionality. However, anisometric rod-like or disk-like molecules used to be a fundamental prerequisite for conventional thermotropic liquid crystal formation, because steric packing considerations play an important role in this interesting state of soft matter. ${ }^{1-3}$ Over many years a large number of liquid-crystalline compounds containing heterocyclic units has been synthesized. ${ }^{4-6}$ This research field has grown even more in recent years because of improvements in synthetic methodologies. Heterocycles are of great importance as core units in thermotropic liquid crystals owing to their 
ability to impart lateral and/or longitudinal dipoles combined with changes in the molecular shape. ${ }^{7,8}$ Furthermore, the incorporation of heteroatoms can result in considerable changes in the corresponding liquid-crystalline phases and/or in the physical properties of the observed phases, because most of the heteroatoms $(\mathrm{S}, \mathrm{O}$, and $\mathrm{N}$ ) commonly introduced are more polarizable than carbon. ${ }^{9}$ Previous works show that five-membered heteroaromatic rings present mesophases and that the presence of a heteroatom can cause profound changes in mesomorphic behavior, due to the electronegativity difference presented in relation to carbon or through changes in molecular geometry. ${ }^{3,4}$

The heterocyclic compounds are used because they are easily prepared and present a large dipolar moment. ${ }^{5,6}$ A disubstituted five-membered ring is not collinear and this causes a significant loss of linearity, disfavoring the mesophases formation. ${ }^{8,9}$ However, the fivemembered ring heterocyclics have been studied as structural units to liquid crystals contributing to the study of the relation between molecular structure and mesomorphic properties. ${ }^{10,11}$

The goal of this study was the synthesis and characterization of the mesomorphic properties of unsymmetrical bent-core molecules based on 2,5-disubstituted tetrazole, where the length of the mesogenic groups as well as polarity varied as shown in Scheme 1. This work represents an extension of our previous work in this field. ${ }^{12}$

\section{Results and Discussion}

The synthetic routes used for the preparation of compounds $\mathbf{6 ( a - d )}$ and 11(a-d) are shown in Schemes 1 and 2. Compounds 6(a-d) were obtained from cyanophenol. Initially a reaction took place with the 1,3-dipolar addition of azide anion $\left(\mathrm{N}_{3}{ }^{-}\right)$to a nitrile, followed by a protection reaction of the phenol group, nucleophilic substitution of bromoalkanes by tetrazolate anion, and phenol de-protection. Compound $\mathbf{5}$ was obtained as reported in the literature. ${ }^{12}$ In the following reaction, esterification reaction took place between the phenol (4) and acid chloride (5) in order to result in Series I compounds (Scheme 1).

Compounds 11(a-d) were also obtained from cyanophenol. Initially an alkylation reaction took place followed by amidoxime formation reaction. In the subsequent reaction, the oxadiazole heterocyclic was prepared by reaction of amidoxime (8) with acid chloride. In the following stage, alkaline hydrolysis of the cyano group gave the carboxylic acid $\mathbf{1 0}$, which was esterified in order to get the Series II compounds (Scheme 2).

All compounds of Series I and II, were synthesized, and characterized by elemental analysis, nuclear magnetic resonance and infrared spectroscopy. The transition temperatures were determined by optical- texture observation using a polarizing microscope equipped with a hot stage, and are listed in Tables 1 and 2. In order to establish the effects of varying the terminal alkoxy- chain-length and mesogenic core on the mesomorphic behavior, two series were synthesized and their mesomorphic behaviors characterized. Table 1 shows the variation of the transition temperatures $(\Delta \mathrm{T})$ and mesomorphic behavior as a function of the number of carbon 
atoms (n) in the alkyl chain. In series I (Scheme 1), all synthesized compounds exhibited liquid crystalline behavior and showed enantiotropic smectic $\mathrm{C}$ and nematic phases. For the homologue with $n=6$ the mesophase stability range was $38.7^{\circ} \mathrm{C}$, similar to the homologue with $n=8$. The highest value observed for the variation of the transition temperatures $(\Delta \mathrm{T})$ was the homolog with $n=10$, which was $50.6^{\circ} \mathrm{C}$. For these compounds it is clear that the SmC phase stability increases with the elongation of the terminal alkyl chain.
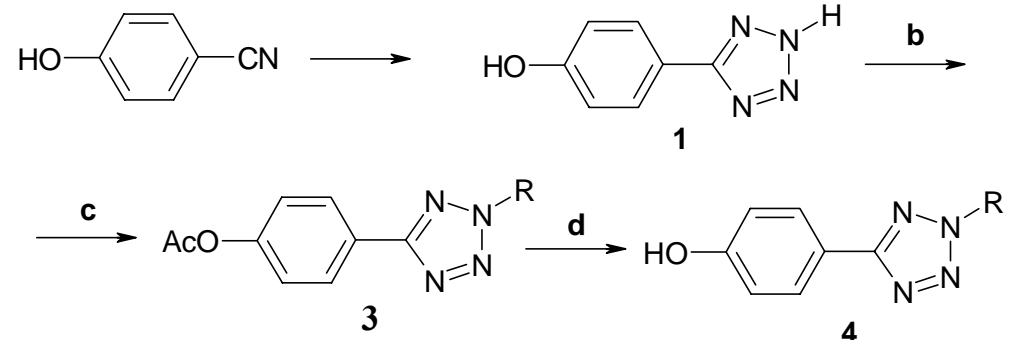

3
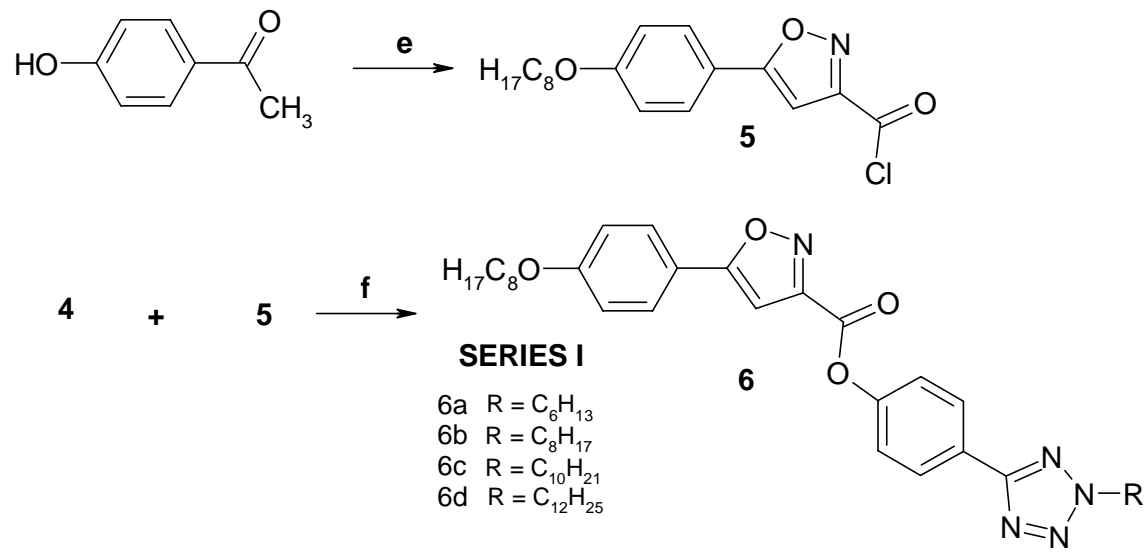

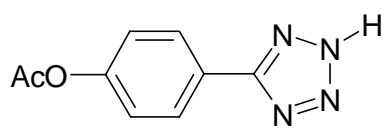

2

Scheme 1. Reaction conditions: (a) $\mathrm{NaN}_{3} / \mathrm{NH}_{4} \mathrm{Cl} / \mathrm{DMF}$, yield 79\%; (b) $\mathrm{Ac}_{2} \mathrm{O}, \mathrm{NaOH}$, yield 78\%; (c) $\mathrm{RBr} / \mathrm{K}_{2} \mathrm{CO}_{3}$, acetone, yield 30-49\%; (d) $\mathrm{KOH} / \mathrm{EtOH} / \mathrm{H}_{2} \mathrm{O}$, yield 30-89\%; (e) The syntheses of compound 5 are reported in the literature; ${ }^{12}$ (e1) diethyl oxalate, $\mathrm{NaH}, \mathrm{DME}, 0^{\circ} \mathrm{C}, 3 \mathrm{~h} ;(\mathrm{e} 2)$ $\mathrm{NH}_{2} \mathrm{OH} . \mathrm{HCl}, \mathrm{Et}_{3} \mathrm{~N}, \mathrm{EtOH}$, reflux, 4 h; (e3) $\mathrm{SOCl}_{2}$, reflux, 5 h, yield 35\% (f) pyridine 10-12\%.

The structural aspect in these compounds is the conjugation of the alkoxy group (OR) with the isoxazole ring, which leads to polarization. Therefore, the chemical structure has a strong dipolar moment increasing the molecular polarizability, overlapping the dipolar moment due to inter-annular conjugation in the 5-aryltetrazole systems that involve a weak resonance and electron- donation for the tetrazole ring, and this should be an important factor for the destabilization of the mesophase. The stability of the mesophase is affected by the polarity of the mesogenic group and is stabilized completely through polar interactions between adjacent chains. The isoxazole group increases the polar interaction between adjacent chains.

For the nematic mesophase, the formation of droplets with Schlieren optical texture with a strong tendency to form homeotropic texture was observed, and for the smectic $\mathrm{C}$ phase the 
characteristic formation of striated texture that evolves to the finally texture focal conic was observed.

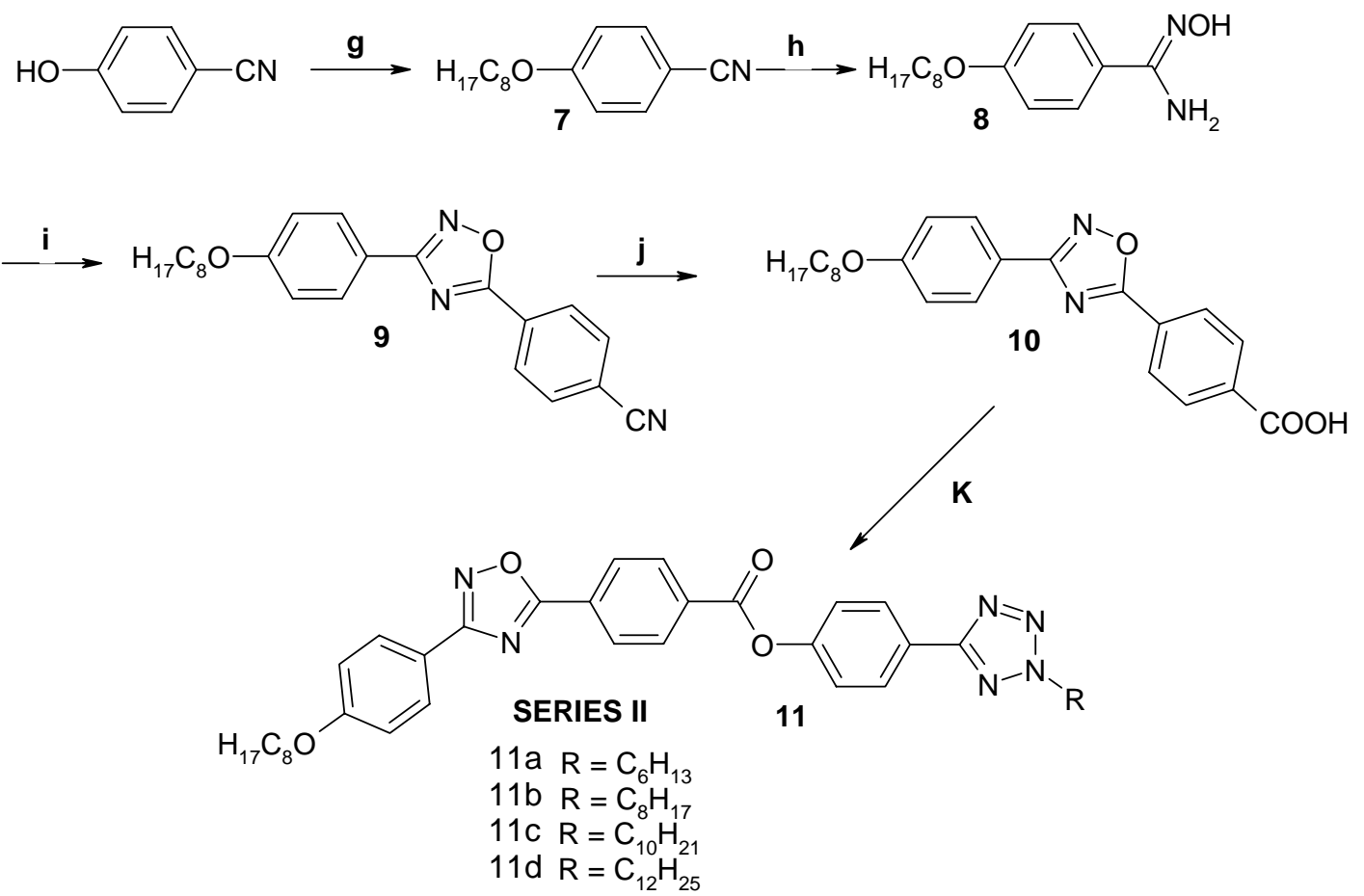

Scheme 2. Reaction conditions: (g) $\mathrm{RBr} / \mathrm{K}_{2} \mathrm{CO}_{3}$, acetone, yield 58\%; (h) $\mathrm{NH}_{2} \mathrm{OH} . \mathrm{HCl} / \mathrm{EtOH}$, $\mathrm{NaOH}, \mathrm{H}_{2} \mathrm{O}$, yield 81\%; (i) 4-cyanobenzoyl chloride, pyridine, yield 44\%; (j) 1. NaOH/EtOH, 2. $\mathrm{HCl}$, yield 80\%; (k) 4, DCC/DMAP, $\mathrm{CH}_{2} \mathrm{Cl}_{2}, 10-22 \%$.

Table 1. Transition temperatures $\left({ }^{\circ} \mathrm{C}\right)$ and yields for the 4-[5-(2-n-alkyltetrazolyl)] phenyl-3carboxy-5'-(4'-octyloxyphenyl)isoxazoles (Series I)

\begin{tabular}{cccccccc}
\hline Compounds & $\boldsymbol{n}$ & $K$ & $\mathbf{S m}_{\mathbf{C}}$ & $\boldsymbol{N}$ & $\mathbf{I}$ & $\Delta \mathbf{T}\left({ }^{\mathbf{0}} \mathbf{C}\right)$ & Yield (\%) \\
$\mathbf{6 a}$ & 6 & 113.8 & 118.4 & 152.5 &. & 38.7 & 40 \\
$\mathbf{6 b}$ & 8 & 107.4 & 117.1 & 146.6 &. & 39.2 & 34 \\
$\mathbf{6 c}$ & 10 & 97.0 & 125.8 & 147.6 &. & 50.6 & 25 \\
$\mathbf{6 d}$ & 12 & 111.2 & 133.8 & 146.5 &. & 35.3 & 41 \\
\hline
\end{tabular}

$N=$ Number of carbon atoms; $K=$ crystalline phase; $\mathrm{Sm}_{\mathrm{C}}=$ smectic $\mathrm{C}$ phase; $\mathrm{N}=$ nematic phase; $\mathrm{I}=$ isotropic phase; $\Delta \mathrm{T}=$ variation of the temperature of phase transition

Table 2 shows the variation of the transition temperatures $(\Delta \mathrm{T})$ and mesomorphic behavior as a function of the number of carbon atoms $(n)$ in the alkyl chain in series II (Scheme 2). All synthesized compounds exhibited liquid crystalline behavior and showed enantiotropic smectic 
C, smectic A and nematic phases. As can be observed in Table 2, for the homolog with $n=6$, the mesophase stability range was $104.8{ }^{\circ} \mathrm{C}$, decreasing to $93.8{ }^{\circ} \mathrm{C}$ to the homolog with $n=8$, and then increasing to the homolog with $n=10$ to $102.5{ }^{\circ} \mathrm{C}$. The increase of the number of carbon atoms in the alkyl chain causes an increase in the existence range of the smectic $\mathrm{C}$ mesophase, to the detriment of the smectic A and nematic mesophases. This is expected because the long aliphatic chains favor the smectic $\mathrm{C}$ phase formation.

The melting point shows an increase in the beginning from $106.3^{\circ} \mathrm{C}$ for the homologue with $n=6$ to $108.1^{\circ} \mathrm{C}$ for $n=10$, and then decreasing for the homologue with $n=12$ to $101.7^{\circ} \mathrm{C}$.

The presence of the dipolar moment perpendicular to the long molecular axis is favorable to the smectic phase formation. Another factor is the electron-withdrawing ester group that destabilizes the interaction between molecules, as it reduces the resonance interaction and modifies the dipole moment of the molecule.

The adequate geometric anisotropy (ratio between length and width of the molecule) is an important point. The molecule extension from $n=6$ to $n=8$ raises the transition temperature $S m_{C}, \mathrm{Sm}_{\mathrm{A}}$, and $\mathrm{Sm}_{\mathrm{A}}-\mathrm{N}$, i.e., it raises the thermal stability of the smectic mesophase. The texture of the nematic mesophase is Schlieren type and it is focal conic type for the mesophase $\mathrm{Sm}_{\mathrm{A}}$. In the case of the $\mathrm{Sm}_{\mathrm{C}}$ mesophase, the characteristic formation of Schlieren texture was observed.

Table 2. Transition temperatures $\left({ }^{\circ} \mathrm{C}\right)$ and yielding for the (4-[5-(2-alkyltetrazolyl)]phenyl-5 benzoyloxy-3-(4`octyloxyphenyl)-1,2,4-oxadiazoles (Series II)

\begin{tabular}{ccccccccc}
\hline Compounds & $\boldsymbol{n}$ & $\boldsymbol{K}$ & $\mathbf{S m}_{\mathbf{C}}$ & $\mathbf{S m}_{\mathbf{A}}$ & $\boldsymbol{N}$ & $\boldsymbol{I}$ & $\boldsymbol{\Delta T}\left(\mathbf{(}^{\mathbf{C}} \mathbf{C}\right)$ & Yield (\%) \\
$\mathbf{1 1 a}$ & 6 & 106.3 & 135.0 & 158.2 & 211.1 &. & 104.8 & 22 \\
$\mathbf{1 1 b}$ & 8 & 107.7 & 163.7 & 193.8 & 201.5 &. & 93.8 & 10 \\
$\mathbf{1 1 c}$ & 10 & 108.1 & 163.4 & 176.2 & 210.6 &. & 102.5 & 21 \\
$\mathbf{1 1 d}$ & 12 & 101.7 & 159.5 & 179.0 & 194.4 &. & 92.7 & 12 \\
\hline
\end{tabular}

$N=$ Number of carbon atoms; $K=$ crystalline phase; $\mathrm{Sm}_{\mathrm{C}}=$ smectic $\mathrm{C}$ phase; $N=$ nematic phase; $I=$ isotropic phase; $\Delta T=$ variation of the temperature of phase transition

When the two series obtained are compared, it is possible to observe that the introduction of an additional aromatic ring (benzene ring) in the series II along with the 1,2,4-oxadiazole heterocyclic favored the formation of the smectic A mesophase, which does not appear in the series I. This suggests that the presence of the benzene ring increases the length and linearity of rigid core of the molecule. The presence of the 1,2,4-oxadiazole ring increases the polarizability of the molecule, favoring the formation of the smectic A mesophase. 


\section{Experimental Section}

General Procedures. All reagents used in the synthesis were purchased from Aldrich Chemical Company (USA) and the solvents were used as received from Merck, Vetec, Baker, Fluka Chemika, Acros and Grupo Química. Elemental analyses were performed using a Carlo Erba EA model 1110. Infrared spectra were recorded on a Shimadzu Prestige 21 spectrometer in $\mathrm{KBr}$ disks or films. ${ }^{1} \mathrm{H}$ - and ${ }^{13} \mathrm{C}$ - nuclear magnetic resonance spectra were recorded using a Bruker AW 200 spectrometer at 200 or $400 \mathrm{MHz}$, and $50.3 \mathrm{MHz}$, respectively. Chemical shifts are reported relative to tetramethylsilane and in units of ppm. The texture and transition temperatures for compounds were observed by optical microscopy using an Olympus BX 50 polarizing microscope in conjunction with a Mettler FP 82 heating stage.

\section{Synthesis of the materials}

5-(4-Hydroxyphenyl)tetrazole (1). ${ }^{12}$ A suspension of $0.042 \mathrm{~mol}$ of 4-hydroxybenzonitrile, $11.015 \mathrm{~g}(0.170 \mathrm{~mol})$ of sodium azide, and $9.012 \mathrm{~g}(0.170 \mathrm{~mol})$ of ammonium chloride in $28 \mathrm{ml}$ of dimethylformamide was stirred for $11 \mathrm{~h}$ at $150^{\circ} \mathrm{C}$. After cooling, the reaction mixture was poured into $100 \mathrm{ml}$ of iced water, and the formed solid was isolated by suction filtration and washed with iced water. Purification by recrystallization in water gave an orange solid, yield 79.0\%, mp 238.0-238. ${ }^{\circ} \mathrm{C}$.

5-(4-Acetoxyphenyl)tetrazole (2). ${ }^{12}$ To a $3 M$ solution of sodium hydroxide (26.7 $\mathrm{ml}$ ) was added 5-(4-hydroxyphenyl)tetrazole (1) (5.385 g, $0.033 \mathrm{~mol}$ ) under magnetic stirring. Ice and acetic anhydride $(0.084 \mathrm{~mol})$ were then added and the mixture was stirred vigorously for 10 to $15 \mathrm{~min}$, forming a precipitate that was isolated by filtration, washed with cold water and recrystallized in water; yield $78.0 \%$ and $\mathrm{mp} 186.3-187.4^{\circ} \mathrm{C}$. IR $\left(\mathrm{KBr}, \mathrm{cm}^{-1}\right) v_{\max }$ : 1756, 1612, 1504, 1440, 1364 , 1282, 1206.

5-(4-Acetoxyphenyl)-2-n-alkyltetrazoles (3). A solution of 5-(4-acetoxyphenyl)tetrazole (2) ( $2.505 \mathrm{~g}, 0.012 \mathrm{~mol})$, the appropriate alkyl bromide $(0.012 \mathrm{~mol})$, potassium carbonate $(1.650 \mathrm{~g}$, $0.012 \mathrm{~mol}$ ) and acetone (30 ml) was refluxed for $44 \mathrm{~h}$, cooled to room temperature, and the solid formed was filtered off. The solvent was concentrated in a rotary evaporator and the residue was recrystallized with ethanol.

5-(4-Acetoxyphenyl)-2-dodecyltetrazole (3d). Recrystallization from ethanol gave a white solid; yield 30.0\%, mp 62.8-64.1 ${ }^{\circ} \mathrm{C}$. IR (KBr, cm $\left.{ }^{-1}\right) v_{\max }: 2914,2858,1762,1535,1230$.

${ }^{1} \mathrm{H}$ NMR (200 MHz, $\left.\mathrm{CDCl}_{3}\right) \delta=8.20$ (d, $J=8.6 \mathrm{~Hz}, 2 \mathrm{H},-\mathrm{C}_{6} \mathrm{H}_{4^{-}}$); 7.25 (d, $J=8.6 \mathrm{~Hz}, 2 \mathrm{H},-\mathrm{C}_{6} \mathrm{H}_{4^{-}}$); 4.66 (t, $J=7.1,2 \mathrm{H},-\mathrm{NC}_{2}$ ); 2.35 (s, 3H, $\left.-\mathrm{COCH}_{3}\right) ; 2.07$ (m, 2H, $\left.-\mathrm{NCH}_{2} \underline{\mathrm{C}}_{2}\right) ; 1.35-1.25$ (m, 9H, $\left.-\mathrm{CH}_{2}\right) ; 0.84\left(\mathrm{t}, \mathrm{J}=6.8 \mathrm{~Hz}, 3 \mathrm{H},-\mathrm{CH}_{3}\right)$.

5-(4-Acetoxyphenyl)-2-hexyltetrazole (3a). Recrystallization from ethanol gave a white solid; yield $44.0 \%$, mp $30.0-31.2^{\circ} \mathrm{C}$.

5-(4-Acetoxyphenyl)-2-octyltetrazole (3b). Recrystallization from ethanol gave a white solid; yield $43.0 \%$, mp $36.6-37.6^{\circ} \mathrm{C}$. 
5-(4-Acetoxyphenyl)-2-decyltetrazole (3c). Recrystallization from ethanol gave a white solid; yield $49.0 \%$, mp $56.1-57.4^{\circ} \mathrm{C}$.

5-(4-Hydroxyphenyl)-2-n-alkyltetrazoles (4). A solution of 5-(4-acetoxyphenyl)-2-alkyltetrazole, 3 (3.75 mmol) in $25.6 \mathrm{ml}$ of ethanol, and a solution of potassium hydroxide (3.75 mmol of $\mathrm{KOH}$ in $5.8 \mathrm{ml}$ of water) was heated at reflux for $12 \mathrm{~h}$. After cooling to room temperature, the solid formed was filtered and the solvent evaporated. The reaction mixture was poured onto $150 \mathrm{~g}$ of ice and acidified with hydrochloric acid. The solid formed was filtered off, and purified by recrystallization.

5-(4-Hydroxyphenyl)-2-octyltetrazole (4b). Recrystallization from hexane gave a white solid; yield $30.0 \%$, mp $65.3-65.9^{\circ} \mathrm{C}$. IR $\left(\mathrm{KBr}, \mathrm{cm}^{-1}\right) v_{\max } 3500,3023,1618,1514,1468,1412,1280 .{ }^{1} \mathrm{H}$ NMR (200 MHz, $\left.\mathrm{CDCl}_{3}\right) \delta=8.00\left(\mathrm{~d}, J=8.6 \mathrm{~Hz}, 2 \mathrm{H},-\mathrm{C}_{6} \mathrm{H}_{4^{-}}\right)$; $6.96\left(2 \mathrm{~d}, J=8.6 \mathrm{~Hz}, 2 \mathrm{H},-\mathrm{C}_{6} \mathrm{H}_{4^{-}}\right)$; 4.61 (t, $\left.J=6.3 \mathrm{~Hz}, 2 \mathrm{H},-\mathrm{NC}_{2}\right) ; 2.00$ (m, 2H, $\left.-\mathrm{NCH}_{2} \underline{\mathrm{C}}_{2}\right) ; 1.34-1.24$ (m, 10H, $\left.-\mathrm{CH}_{2}\right) ; 0.87$ (t, $\left.J=6.8 \mathrm{~Hz}, 3 \mathrm{H},-\mathrm{CH}_{3}\right)$.

5-(4-Hydroxyphenyl)-2-hexyltetrazole (4a). Recrystallized from hexane; a white solid; yield 89.0\%, mp 67.5-68. ${ }^{\circ} \mathrm{C}$.

5-(4-Hydroxyphenyl)-2-decyltetrazole (4c). Recrystallized from hexane; a white solid; yield 53.0\%, mp 73.4-76. ${ }^{\circ} \mathrm{C}$.

5-(4-Hydroxyphenyl)-2-dodecyltetrazole (4d). Recrystallized from hexane; a white solid; yield 54.0\%, mp 67.6-68.9 $\mathrm{C}$.

5-(4-Octyloxyphenyl)-3-isoxazolylcarboxyl chloride (5) was prepared as described. ${ }^{12}$

\section{General procedure for synthesis of the homologous series I}

4-[5-(2-n-Alkyltetrazolyl)]phenyl-3-carboxy-5'-(4'-octyloxyphenyl)isoxazole (6). 5-(4Hydroxyphenyl)-2-n-alkyltetrazoles (4) (1.54 mmol) were added in previously distilled pyridine. The previously prepared acid chloride (5) was added and the reaction mixture was stirred for 24h at room temperature. After this, the reaction mixture was heated to $40^{\circ} \mathrm{C}$ for $30 \mathrm{~min}$, cooled to room temperature and poured into ice and water $(50 \mathrm{ml})$. The formed solid was filtered off and recrystallized from ethanol.

4-[5-(2-Octyltetrazolyl)]phenyl-3-carboxy-5'-(4'-octyloxyphenyl)isoxazole (6b). IR ( $\mathrm{KBr}$, $\mathrm{cm}^{-1}$ ) $v_{\max }: 2920,2852,1751,1613,1507,1448,1258,1226,831 .{ }^{1} \mathrm{H}$ NMR (400 MHz, $\left.\mathrm{CDCl}_{3}\right) \delta$ $=8.25\left(\mathrm{~d}, J=8.6 \mathrm{~Hz}, 2 \mathrm{H},-\mathrm{C}_{6} \mathrm{H}_{4}-\right) ; 7.41$ (d, $\left.J=8.6 \mathrm{~Hz}, 2 \mathrm{H},-\mathrm{C}_{6} \mathrm{H}_{4^{-}}\right) ; 7.77$ (d, J=8.6 Hz, 2H, $-\mathrm{C}_{6} \mathrm{H}_{4^{-}}$); 7.00 (d, $J=8.6 \mathrm{~Hz}, 2 \mathrm{H},-\mathrm{C}_{6} \mathrm{H}_{4}-$ ); 6.94 (s, $1 \mathrm{H},-\mathrm{CH}$ of the isoxazole ring); 4.65 (t, $J=7.14 \mathrm{~Hz}, 2 \mathrm{H}$, $\mathrm{NCH}_{2}$ ); 4.02 (t, 2H, $-\mathrm{OCH}_{2}$ ); 2.06 (q, $\left.2 \mathrm{H},-\mathrm{NCH}_{2} \mathrm{CH}_{2}\right) ; 1.82$ (m, $\left.2 \mathrm{H},-\mathrm{OCH}_{2} \underline{\mathrm{C}}_{2}\right) ; 1.29$ (m, 20H, $-\mathrm{CH}_{2}$ ); 0.89 (t, $J=6.6 \mathrm{~Hz}, 6 \mathrm{H},-\mathrm{CH}_{3}$ ). Anal. Calcd for $\mathrm{C}_{33} \mathrm{H}_{43} \mathrm{O}_{4} \mathrm{~N}_{5}$ : C, 69.08; H, 7.55; N, 12.21. Found C, 69.12; H, 7.58; N, 2.44\%.

4-[5-(2-Hexyltetrazolyl)]phenyl-3-carboxy-5'-(4'-octyloxyphenyl)isoxazole (6a): IR ( $\mathrm{KBr}$, $\left.\mathrm{cm}^{-1}\right) v_{\max }: 2953,2918,1751,1614,1447,1261,1228 \mathrm{~cm}^{-1}$.

4-[5-(2-Decyltetrazolyl)]phenyl-3-carboxy-5'-(4'-octyloxyphenyl)isoxazole (6c): IR ( $\mathrm{KBr}$, $\mathrm{cm}^{-1}$ ) $v_{\max }: 2920,2850,1753,1614,1464,1448,1259,1226 \mathrm{~cm}^{-1}$. 
4-[5-(2-Dodecyltetrazolyl)]phenyl-3-carboxy-5'-(4'-octyloxyphenyl)isoxazole (6d): IR (KBr, $\left.\mathrm{cm}^{-1}\right) v_{\max }: 2970,2858,1733,1655,1423,1449,1244,1238 \mathrm{~cm}^{-1}$.

4-Octyloxybenzonitrile (7). This compound was prepared as described. ${ }^{13} \mathrm{~A}$ mixture of $p$ cyanophenol $(0.0167 \mathrm{~mol})$, potassium carbonate $(0.0167 \mathrm{~mol})$ and acetone $(50 \mathrm{ml})$ was heated at $70^{\circ} \mathrm{C}$ for several minutes. Then octyl bromide $(0.0167 \mathrm{~mol})$ was added dropwise and the reaction mixture refluxed for $72 \mathrm{~h}$. After filtration and evaporation of the solvent, the solid residue was purified by recrystallization from ethanol and water (5:1).Yield 58\% and mp. 26.7-27.0 ${ }^{\circ} \mathrm{C}$.

4-Octyloxybenzamidoxime (8). To a solution of (5.84 mmol) hydroxylamine hydrochloride in a mixture of $(5.84 \mathrm{mmol})$ sodium hydroxide in $0.32 \mathrm{ml}$ of water was added a solution of (5.19 mmol) 4-octyloxybenzonitrile (7) in $15 \mathrm{ml}$ of ethanol. The mixture was heated under reflux for $3 \mathrm{~h}$. After the mixture was cooled in a freezer for $24 \mathrm{~h}$, white crystals were collected by filtration and dried. The crystals were recrystallized from hexane. Yield $81 \%$ and mp. 84.5$85.5^{\circ} \mathrm{C}$.

5-(4-Cyanophenyl)-3-(4-octyloxyphenyl)-1,2,4-oxadiazole (9). 4-octyloxy-benzamidoxime (8) $(1.89 \mathrm{mmol})$ was dissolved in dry pyridine $(6.30 \mathrm{ml})$. The $p$-cyanobenzoyl chloride $(1.89 \mathrm{mmol})$ was then added. The mixture was heated under reflux for $5 \mathrm{~h}$ and the cooled reaction mixture was poured into water $(100 \mathrm{ml})$. The crude product was purified by recrystallization from ethanol. Elemental analysis results (CHN) were satisfactory. Yield 44.0\%; mp. 134.4-135.2 ${ }^{\circ} \mathrm{C}$. IR (KBr, $\left.\mathrm{cm}^{-1}\right) v_{\max }: 2922,2850,2231,1608,1587,1552,1249,1172,839$.

5-(4-Carboxyphenyl)-3-(4-octyloxyphenyl)-1,2,4-oxadiazole (10). 5-(4-Cyanophenyl)-3-(4octyloxyphenyl)-1,2,4-oxadiazole (9) $(0.58 \mathrm{mmol})$ was dissolved in ethanol $(30 \mathrm{ml})$ and a solution $20 \%$ of sodium hydroxide $(1.2 \mathrm{ml})$ was added. The reaction mixture was refluxed for $7 \mathrm{~h}$. The cooled reaction mixture was acidified with hydrochloride acid $2 \mathrm{M}$ and the precipitated formed was filtered off and washed with iced water. The obtained solid was recrystallized from ethanol. Yield 80.0\%; mp. 218.0-219.0 ${ }^{\circ} \mathrm{C}$. IR $\left(\mathrm{KBr}, \mathrm{cm}^{-1}\right) v_{\max }$ : 3500, 2920, 1689, 1469, 1425, 1253, 1172.

\section{General procedure for synthesis of the homologous series II}

4-[5-(2-n-Alkyltetrazolyl)]phenyl-5'-benzoyloxy-3-(4'-octyloxyphenyl)-1,2,4-oxadiazole

(11). 5-(4-Carboxyphenyl)-3-(4-octyloxyphenyl)-1,2,4-oxadiazole (10) $(0.50 \mathrm{mmol})$ and the 5(4-hydroxyphenyl)-2-n-alkyltetrazole (4) $(0.44 \mathrm{mmol})$ were dissolved in dry methylene chloride $(7 \mathrm{ml})$. Then DCC $(0.50 \mathrm{mmol})$ and DMAP $(0.0075 \mathrm{~g})$ as catalyst were added. The reaction mixture was stirred for $48 \mathrm{hr}$ at room temperature. The formed solid was filtered off and the solvent was evaporated. The obtained solid was purified by recrystallization from ethanol yielding the esters (11).

11a. Yield 22.0\%; IR $\left(\mathrm{KBr}, \mathrm{cm}^{-1}\right) v_{\max }$ : 2931, 2920, 1728, 1464, 1268, 1254. ${ }^{1} \mathrm{H}$ NMR (400 $\left.\mathrm{MHz}, \mathrm{CDCl}_{3}\right) \delta=8.38$ (s, $4 \mathrm{H},-\mathrm{C}_{6} \mathrm{H}_{4}$ - central); 8.25 (d, $J=8.4 \mathrm{~Hz}, 2 \mathrm{H},-\mathrm{C}_{6} \mathrm{H}_{4}-$ linked to tetrazole); 7.39 (d, $J=8.4 \mathrm{~Hz}, 2 \mathrm{H},-\mathrm{C}_{6} \mathrm{H}_{4}$ - linked to tetrazole); 8.11 (d, $J=8.4 \mathrm{~Hz}, 2 \mathrm{H},-\mathrm{C}_{6} \mathrm{H}_{4}$ - linked to 1,2,4oxadiazole); 7.02 (d, $J=8.4 \mathrm{~Hz}, 2 \mathrm{H},-\mathrm{C}_{6} \mathrm{H}_{4}$ - linked to 1,2,4-oxadiazole); 4.66 (t, $J=7.15 \mathrm{~Hz}, 2 \mathrm{H},-$ $\left.\mathrm{NC}_{2}\right) ; 4.03\left(\mathrm{t}, 2 \mathrm{H},-\mathrm{OCH}_{2}\right) ; 1.70\left(\mathrm{~m}, 20 \mathrm{H},-\mathrm{CH}_{2}\right) ; 0.89\left(\mathrm{t}, J=6,5 \mathrm{~Hz}, 6 \mathrm{H},-\mathrm{CH}_{3}\right) .{ }^{13} \mathrm{C} \mathrm{NMR}$ 
(50.3 $\left.\mathrm{MHz} \mathrm{CDCl}_{3}\right) \delta=174.52,169.25,164.50,164.16,161.97,152.38,132.95,131.08,129.38$, 129.01, 128.55, 128.44, 125.87, 122.41, 118.97, 115.05, 68.43, 53.52, 32.05, 31.28, 29.58, 29.47, 29.41, 26.26, 22.90, 22.63, 14.35, 14.17. Anal. Calcd for $\mathrm{C}_{36} \mathrm{H}_{42} \mathrm{~N}_{6} \mathrm{O}_{4} ; \mathrm{C}, 69.43 ; \mathrm{H}, 6.81 ; \mathrm{N}$, 13.49. Found C, 68.52; H, 6.86; N, 13.52\%.

11b. Yield 10.0\%; IR (KBr, $\mathrm{cm}^{-1}$ ) $v_{\max }$ : 2920, 2851, 1728, 1613, 1464, 1269, 1254. ${ }^{1} \mathrm{H}$ NMR $\left(400 \mathrm{MHz}, \mathrm{CDCl}_{3}\right) \delta=8.37$ (s, 4H, $-\mathrm{C}_{6} \mathrm{H}_{4}$ - central); 8.25 (d, J=8.4 Hz, $2 \mathrm{H},-\mathrm{C}_{6} \mathrm{H}_{4}$ - linked to tetrazole); 7.39 (d, J=8.4 Hz, 2H, $-\mathrm{C}_{6} \mathrm{H}_{4}$ - linked to tetrazole); 8.11 (d, J=8.4 Hz, 2H, $-\mathrm{C}_{6} \mathrm{H}_{4}$ linked to 1,2,4-oxadiazole); 7.01 (d, $J=8.4 \mathrm{~Hz}, 2 \mathrm{H},-\mathrm{C}_{6} \mathrm{H}_{4}$ - linked to 1,2,4-oxadiazole); 4.65 (t, $\left.J=7.2 \mathrm{~Hz}, 2 \mathrm{H},-\mathrm{NC}_{2}\right)$; 4.03 (t, 2H, $\left.-\mathrm{OCH}_{2}\right) ; 1.70$ (m, 24H, $\left.-\mathrm{CH}_{2}\right) ; 0.88$ (t, J=6.5 Hz , 6H, $\left.\mathrm{CH}_{3}\right) .{ }^{13} \mathrm{C}$ NMR (50.3 MHz, $\left.\mathrm{CDCl}_{3}\right) \delta=174.51,169.24,164.49,164.16,161.97,152.37,132.95$, 131.09, 129.38, 129.01, 128.54, 128.43, 125.87, 122.40, 118.97, 115.04, 68.43, 53.51, 32.05, 31.92, 29.61, 29.41, 29.25, 29.10, 26.60, 26.26, 22.90, 22.83, 14.35. Calcd for $\mathrm{C}_{38} \mathrm{H}_{46} \mathrm{~N}_{6} \mathrm{O}_{4}$; C, 70.12; H, 7.13; N, 12.91. Found C, 69.92; H, 7.46; N, 13.15\%.

11c. Yield $21.0 \%$. IR $\left(\mathrm{KBr}, \mathrm{cm}^{-1}\right) \mathrm{v}_{\max }$ : 2918, 2852, 1739, 1614, 1464, 1280, 1255. ${ }^{1} \mathrm{H}$ NMR $\left(400 \mathrm{MHz}, \mathrm{CDCl}_{3}\right) \delta=8.31$ (s, 4H, $-\mathrm{C}_{6} \mathrm{H}_{4}$ - central); 8.18 (d, J=8.4 Hz, 2H, $-\mathrm{C}_{6} \mathrm{H}_{4}$ - linked to tetrazole); 7.32 (d, J=8.4 Hz, 2H, $-\mathrm{C}_{6} \mathrm{H}_{4}$ - linked to tetrazole); 8.04 (d, J=8.4 Hz, $2 \mathrm{H},-\mathrm{C}_{6} \mathrm{H}_{4}$ linked to 1,2,4-oxadiazole); 6.95 (d, $J=8.4 \mathrm{~Hz}, 2 \mathrm{H},-\mathrm{C}_{6} \mathrm{H}_{4}$ - linked to 1,2,4-oxadiazole); 4.58 (t, $J=$ $\left.7.2 \mathrm{~Hz}, 2 \mathrm{H},-\mathrm{NCH}_{2}\right) ; 3.96$ (t, 2H, $\left.-\mathrm{OCH}_{2}\right) ; 1.70\left(\mathrm{~m}, 28 \mathrm{H},-\mathrm{CH}_{2}\right) ; 0.82$ (t, J=6,4 Hz, 6H, $\left.-\mathrm{CH}_{3}\right)$. ${ }^{13} \mathrm{C} \mathrm{NMR}\left(50.3 \mathrm{MHz}, \mathrm{CDCl}_{3}\right) \delta=174.52,169.24,164.50,164.17,161.97,152.37,132.95$, 131.09, 129.38, 129.01, 128.55, 128.44, 125.87, 122.40, 118.96, 115.05, 68.42, 53.51, 32.04, 31.92, 31.18, 29.61, 29.47, 29.40, 29.24, 29.09, 26.56, 26.25, 22.89, 22.83, 14.35, 14.31.

11d. Yield 12.0\%; IR (KBr, $\left.\mathrm{cm}^{-1}\right) v_{\max }$ : 2918, 2848, 1724, 1614, 1463, 1271, 1255, 750. ${ }^{1} \mathrm{H}$ NMR (400 MHz, $\mathrm{CDCl}_{3}$ ) $\delta=8.39$ (s, 4H, - $\mathrm{C}_{6} \mathrm{H}_{4}$ - central); 8.25 (d, J=8.4 Hz, 2H, - $\mathrm{C}_{6} \mathrm{H}_{4}$ - linked to tetrazole); 7.39 (d, $J=8.4 \mathrm{~Hz}, 2 \mathrm{H},-\mathrm{C}_{6} \mathrm{H}_{4}$ - linked to tetrazole); 8.11 (d, J=8.4 Hz, $2 \mathrm{H},-\mathrm{C}_{6} \mathrm{H}_{4}$ linked to 1,2,4-oxadiazole); 7.02 (d, $J=8.4 \mathrm{~Hz}, 2 \mathrm{H},-\mathrm{C}_{6} \mathrm{H}_{4}$ - linked to 1,2,4-oxadiazole); 4.66 (t, $J=$ $\left.7.2 \mathrm{~Hz}, 2 \mathrm{H},-\mathrm{NCH}_{2}\right) ; 4.04$ (t, 2H, $\left.-\mathrm{OCH}_{2}\right) ; 1.60$ (m, 32H, $\left.-\mathrm{CH}_{2}\right) ; 0.87$ (t, J=6.5 Hz, 6H, $-\mathrm{CH}_{3}$ ).

${ }^{13} \mathrm{C} \mathrm{NMR}\left(50.3 \mathrm{MHz}, \mathrm{CDCl}_{3}\right) \delta=174.53,169.25,164.51,164.18,161.98,152.38,132.96$, 131.09, 129.39, 129.02, 128.56, 128.45, 125.88, 122.41, 118.97, 115.06, 68.43, 53.53, 49.43, 34.16, 32.13, 32.05, 29.83, 29.72, 29.58, 29.47, 29.41, 29.13, 26.60, 26.25, 25.83, 25.16, 22.91, 14.35. Anal. Calcd for $\mathrm{C}_{42} \mathrm{H}_{54} \mathrm{~N}_{6} \mathrm{O}_{4}$ : C, 71.35; H, 7.71; N, 11.89. Found: C, 70.51; H, 8.02; N, $12.25 \%$.

\section{Acknowledgements}

The authors gratefully acknowledge the financial support of FURB, FAPESC, UNIVALI and UNISUL. 


\section{References}

1. Demus, D.; Goodby, J.; Gray G. W.; Spiess, H.-W.in Handbook of Liquid Crystals, Vill, V., Ed.: VCH-Wiley: Weinheim, 1998.

2. (a) Cai, R.; E. Samulski, T. Liq. Cryst. 1991, 9, 617. (b) Cristiano, R.; Westphal; E.; Bechtold, I. H.; Bortoluzzi, A. J.; Gallardo, H. Tetrahedron 2007, 63, 2851. (c) Vasconcelos, U. B. ; Vilela, G. D.; Schrader, A.; Gorges, A.; Merlo, A. A. Tetrahedron 2008, 64, 4619. (d) Merlo, A. A. ; Vasconcelos, U. B. J. Synthesis 2006, 7, 1141.

3. (a) Gallardo, H.; Maurmann, L. Mol. Cryst. Liq. Cryst. 2002, 378, 23. (b) Gallardo, H.; Silva, F. C. J. Chem. Soc., Perkin Trans. 2 1987, 3, 319.

4. (a) Gallardo, H.; Favarin, I. Liq. Cryst. 1993, 13, 115. (b) Bartulín, J.; Martinez, R.; Gallardo, H.; Muller, H.; Taylor, T. R. Mol. Cryst. Liq. Cryst. 1993, 225, 175-182. (c) Cristiano, R.; Vieira, A. A.; Ely, F.; Gallardo, H. Liq. Cryst. 2006, 33, 381. (d) Aldred M. P.; Vlachos, P.; Dong, D.; Kitney, S. P.; Tsoi, W. C.; O’Neill, M.; Kelly, S. M. Liq. Cryst. 2005, 32, 95. (e) Paraskos, A. J.; Swager, T. M. Chem. Mater. 2002, 14, 4543.

5. (a) Kauhanka, M. U.; Kauhanka, M. M. Liq. Cryst. 2006, 33, 121. (b) Cristiano, R.; Santos, D. M. P. O.; Gallardo, H. Liq. Cryst. 2005, 32, 7. (c) Cristiano, R.; Ely, F.; Gallardo H. Liq. Cryst. 2005, 32, 15.

6 Seed, A. Chem. Soc. Rev. 2007, 36, 2046.

7. (a) Matharu, A. S.; Chambers-Asman, D. Liq Cryst. 2007, 34, 1317. (b) Gallardo, H.; Zucco, C.; Da Silva, L. Mol. Cryst. Liq. Cryst. 2002, 373, 181.

8. Gallardo, H.; Magnago, R. F.; Bortoluzzi, A. J. Liq. Cryst. 2001, 28, 1343.

9. Lai, C. K.; Ke, Y.; Chien-Shen, J. S.; Li, W. Liq. Cryst. 2002, $29,915$.

10. Merlo, A. A.; Gallardo, H.; Taylor, T. R. Quim. Nova 2001, 24, 354.

11. Pereira, F. V.; Borsali, R.; Ritter, O. M. S.; Gonçalves, P. F.; Merlo, A. A.; Silveira N. P. J. Braz. Chem. Soc. 2006, 17, 184.

12. Da Silva, L.; Gallardo, H.; Magnago, R. F.; Begnini, I. M. Mol. Cryst. Liq. Cryst. 2005, 432, 1.

13. Gallardo, H.; Begnini, I. M. Mol. Cryst. Liq. Cryst. 1995, 258, 85. 